\title{
UM CASO DE SUCESSO: METODOLOGIAS QUE POTENCIALIZAM A EDUCAÇÃO AMBIENTAL NO ENSINO FUNDAMENTAL
}

\author{
Douglas Bitencourt Vidal ${ }^{1}$ \\ MonessaTedoldi Nogueira ${ }^{2}$ \\ Thuany Souza Campos ${ }^{3}$
}

Resumo: A Educação Ambiental proporciona dentro da formação escolar uma construção de valores sociais, conhecimentos e atitudes, relacionados a conservação do meio ambiente. A partir desta premissa, objetivou-se neste estudo apresentar as metodologias aplicáveis à Educação Ambiental das Escolas de Ensino Fundamental do município de Montanha-ES, retratando os métodos utilizados por estas escolas para potencializar a aplicabilidade da Educação Ambiental no Ensino Fundamental. O artigo identifica como estas escolas conduzem o processo de produção de conhecimento do discente sobre a consciência crítica na problemática ambiental, para assim retratar suas metodologias. Tornou-se evidente que as escolas questionadas possuem conhecimento à cerca de que a Educação Ambiental precisa ser trabalhada dentro do contexto escolar, bem como na comunidade de maneira transdisciplinar, propiciando ao discente uma consciência crítica na busca de sua transformação social. Nesse sentido, as metodologias apresentadas podem ser uma diretriz viável para outras escolas.

Palavras-chave: Montanha/ES; Ensino Fundamental; COM-VIDA; Educação Ambiental.

1Universidade Federal da Bahia. E-mail: bitencourt douglas@hotmail.com

2 Faculdade Multivix Nova Venécia. E-mail: suprimentosconsultoria@hotmail.com

${ }^{3}$ Faculdade Multivix Nova Venécia. E-mail: camposthuany@gmail.com

Revbea, São Paulo, V. 13, № 4: 66-78, 2018. 


\section{Introdução}

A Educação Ambiental (EA) é responsável por formar cidadãos comprometidos com o contexto ambiental. Deve ser baseada numa perspectiva de educação contínua, onde torna se importante, seu aperfeiçoamento desde a primeira fase da vida escolar, em todas as idades e níveis, tanto da educação formal quanto não formal.

Torna-se evidente que garantir essa formação inicial na EA resulta cidadãos conscientes em relação à problemática ambiental. A mesma contribui consideravelmente proporcionando conhecimentos necessários para uma visão de um mundo melhor e com perspectiva de proteção e conservação ao meio ambiente.

A EA é resguardada por leis, e sob a disposição do Art.1ำ da Política Nacional de Educação Ambiental (PNEA), Lei no 9.795/1999, diz-se:

Entendem-se por Educação Ambiental os processos por meio dos quais o indivíduo e a coletividade constroem valores sociais, conhecimentos, habilidades, atitudes e competências voltadas para a conservação do meio ambiente, bem de uso comum do povo, essencial à sadia qualidade de vida e sua sustentabilidade.

Dias (2013) fala que a EA proporciona às pessoas possibilidades de adquirir novos conhecimentos, tornando-os aptos para buscar soluções dos problemas ambientais, como uma forma de aumentar sua qualidade de vida. Nota-se o quão importante é incluir a EA nas escolas, diante do pensamento do autor.

A criação do artigo se deu por meio da necessidade de analisar as concepções sobre a EA nas escolas. Onde cada vez mais, busca-se uma educação que conscientize as pessoas, desde o início de sua jornada escolar, levando-se em consideração que os métodos de ensino são norteadores no desenvolvimento do processo de ensino-aprendizagem do discente, surgiu à ideia de demonstrar metodologias que potencializam a aplicabilidade da EA no Ensino Fundamental (EF). Visto que a EA deve ser transmitida ao ser humano desde o início de sua vida e que é preciso entender que o futuro depende de uma boa relação entre a natureza e o ser humano, viu-se à importância de explanar tais metodologias pertinentes à EA.

Segundo Dias (2013), deve-se utilizar diversos ambientes educativos e uma ampla gama de métodos para comunicar e adquirir conhecimentos sobre - meio ambiente, acentuando devidamente as atividades práticas e as experiências pessoais. Diante disto, é preciso empregar todos os recursos pedagógicos acessíveis enfatizando as atividades práticas, pois a EA presume ação, garantindo assim o que dispõe na PNEA, em seu art. 5 (Inciso II e III): 
Art. 5o São objetivos fundamentais da Educação Ambiental:

II - a garantia de democratização das informações ambientais;

III - o estímulo e o fortalecimento de uma consciência crítica sobre a problemática ambiental e social;

O objetivo deste trabalho foi apresentar as metodologias aplicáveis à EA das Escolas Municipais de Ensino Fundamental da cidade de Montanha ES, mostrando como as mesmas conduzem o processo de produção de conhecimento do discente sobre a consciência crítica na problemática ambiental.

\section{Metodologia da Pesquisa}

O município de Montanha, localizado no norte do estado do Espírito Santo, com a população estimada de 19.391 (dezenove mil e trezentos e noventa e um) habitantes, dos quais 2.719 (dois mil setecentos e dezenove) habitantes estão matriculados no EF, dentro deste universo são 1.892 (mil oitocentos e noventa e dois) habitantes matriculados na rede pública municipal, que correspondem a alunos matriculados em 09 (nove) escolas que ofertam o $\mathrm{EF}$, levando-se em consideração que estas escolas integram a área urbana e a zona rural, e como objeto de estudo para este artigo foram pesquisadas 05 (cinco) escolas da rede pública que ofertam o EF na área urbana deste município, sendo elas: EMEF Bairro Brasília, EMEF Domingos Martins, EMEF Pedro Palácio, EMEF São Sebastião do Norte e EMEF Maria Clementina. (CENSO 2015, IBGE, 2010).

Para este estudo observou-se como as Escolas Municipais de Montanha oferecem, aplicam e exploram o ensino de EA para a formação crítica e cidadã dos alunos do EF, como forma da preparação do exercício da cidadania, tendo como o fim a demonstração de como a EA deve ser implantada no contexto escolar, para a produção do conhecimento significativo e a relação entre escola, pais ou responsáveis e comunidade.

$\mathrm{O}$ artigo é sustentado por pesquisas bibliográficas, fundamentado e baseado por seguintes documentos: Constituição Federal, Leis, Diretrizes Curriculares, Resoluções, Plano Nacional de Educação (PNE), Política Nacional de Educação Ambiental (PNEA) e o Programa COM-VIDA.

Ao explorar 0 assunto foi elaborado um questionário fechado, no qual fora aplicado em 05 (cinco) Escolas Municipais de Montanha para a coleta de informações, sendo os resultados obtidos mediante análise do questionário e observação espontânea. O questionário fechado apresenta indagações diretas no que tange a como é ofertado e trabalhado à EA nestas escolas, bem como a associação entre a teoria e prática e a relação de como o corpo docente e como a equipe pedagógica tem abordado e introduzido atividades que enfoquem a EA. 
Após a coleta, foi realizada uma análise e produzido um relatório em que foi feita a interpretação de natureza predominantemente qualitativa para que se verificasse se os direitos e a prática no que tange ao assunto EA estão sendo assegurados e garantidos nas escolas pesquisadas.

\section{Referencial Teórico}

\section{Considerações iniciais sobre Educação Ambiental}

Dias (2013) acredita que o conceito da EA seja um procedimento onde as pessoas aprendem como o meio ambiente trabalha a necessidade em relação a ele, como o prejudicamos e como desenvolvemos a sua sustentabilidade. Todavia, passam-se os anos e aumenta-se significativamente a necessidade de conscientização referente à problemática ambiental.

A Educação Ambiental, através de sua especificidade, ou seja, de sua preocupação com a situação geral (mundial) e particular (regional, local), atende e retoma as finalidades amplas da educação. Devemos relembrar que integram essa especificidade o atendimento de fatores que interferem nos problemas ambientais, sob aspectos econômicos, sociais, políticos e ecológicos; a aquisição de conhecimentos, de valores, de atitude, de compromisso e de habilidade necessários para a proteção e melhoria do meio ambiente; a criação de novos padrões de conduta orientados para a preservação e melhoria da qualidade do meio ambiente. (CASTRO E SPAZZIANI, apud LOUREIRO; LAYRARGUES; CASTRO, 2012, p.160).

A questão ambiental está ligada à ideia de risco ambiental, visto que a população cada vez mais percebe que o termo ambiente equilibrado ecologicamente, tornou-se parte elementar vital para a qualidade de vida das pessoas. Em outras palavras, a Constituição Federal de 1988, em seu Art. 225, aponta que é direito de todos possuírem um meio ambiente equilibrado em seu contexto ecológico, bem como uma qualidade de vida sadia, estabelecendo ainda que o poder público defenda-o e preserve-o com destino as novas gerações (LOUREIRO; LAYRARGUES; CASTRO, 2012).

Loureiro, Layrargues e Castro (2012) apresentam que a temática ambiental não é mais preocupação exclusiva a profissionais restritos da área, pois a mesma engloba bem mais que isso, todas as pessoas estão sujeitadas a lidar com as decorrências dos problemas ambientais, isto é, o assunto em questão não se delimita apenas a ecologistas ou outros especialistas da área ambiental, mas sim a toda a população em geral.

Assim fica claro que a EA se tornou realidade nos tempos atuais, suas ações podem ser encontradas em toda sociedade. Por isso a importância da busca de caminhos para uma EA de qualidade e que garanta a 
conscientização, tendo como base inicial o contexto escolar (GUIMARÃES, 2008).

A Educação Ambiental tende a contribuir para formação de pessoas conscientes, capazes de atuar dentro da realidade ambiental. Para tal, se faz necessário ir além dos conceitos, a escola deve comprometer-se a trabalhar formação de atitudes e valores, através do ensino de habilidades e é evidente que isso é um enorme desafio para a educação. Comportamentos precisos e corretos pertencentes à temática ambiental devem ser aprendidos no dia-a-dia, no cotidiano escolar, tais como, solidariedade, higiene do ambiente dentre outras (BRASIL, 2001).

$\mathrm{Na}$ conferência do Rio/92, mais de 170 países marcaram presença e assinaram tratados referentes à função central da educação para a busca da construção de um mundo íntegro em seu contexto social e equilibrado em seu contexto ecológico, sendo que tais medidas requerem compromisso e responsabilidade individual e coletiva. Ressalva-se ainda que com tal prática, é o que se almeja da EA no Brasil (BRASIL, 2001).

No ano de 2004, foi realizada uma pesquisa nas escolas brasileiras, da qual apontou que $42,34 \%$ das escolas elaboravam projetos para a EA, 3,61\% alegaram usufruir nos currículos matérias ligadas a área ambiental e por fim $72 \%$ delataram integrar a temática em suas disciplinas (MEC 2004 apud GUIMARÃES, 2008).

Guimarães (2008) ainda diz que independente dos números o que vale é o tipo de EA que está sendo aplicada e desenvolvida nas escolas e se for feita uma pesquisa mais aprofundada sobre sua qualidade ficará evidente que a sua aplicabilidade não está concordante com os princípios da EA.

Nos dias de hoje, existem ainda dificuldades na recepção da EA no EF e foi percebido que em alguns casos de sucesso, são notáveis indícios de que a EA é trabalhada de formas diferentes.

\section{A história e a legislação desse processo}

A preocupação com a EA inicia se a 40.000 a.C com o desenvolvimento de instrumentos de caça, cozinha e outras tarefas, por menores que sejam as atividades realizadas, estas já causavam um impacto, no qual pode se citar a chegadas dos portugueses ao Brasil para a realização da Segunda Missa, e fez-se uma gigantesca cruz de madeira iniciando a exploração predatória, logo após veio à comercialização do pau-brasil, que devido a exploração incontrolada foi criada a Carta Régia que estabelece normas disciplinares sobre o corte da madeira. No ano de 1875 encerra o ciclo econômico do pau-brasil com as matas exauridas (DIAS, 2013).

Em 1889 o termo EA se faz cada vez mais presente com o escocês Patrick Geddes considerado o pai/fundador da Educação Ambiental (1854 1933) argúi que "Uma criança em contato com a realidade do seu ambiente 
não só aprenderia melhor, mas também desenvolveria atitudes criativas em relação ao mundo em sua volta" (DIAS, 2013, p.3).

Em decorrência dos transtornos ambientais provocados pelo uso demasiado dos recursos naturais acabavam exigindo a criação de novas leis e fundações, como em 1958 a Fundação Brasileira para Conservação da Natureza (FBCN).

Uma das primeiras grandes reuniões para tratar de assuntos relacionados com a EA na tentativa de controlar a exploração dos recursos naturais e que merece destaque é a Conferência de Estocolmo. Após a Conferência de Estocolmo, ocorreu em Belgrado um encontro sobre EA, promovido pela UNESCO, no qual este encontro resultou na confecção da Carta de Belgrado (DIAS, 2013).

No ano de 1977, a Secretaria Especial do Meio Ambiente (Sema) desenvolve documentos voltados à realidade socioeconômica educacional brasileira, neste mesmo ano ocorre uma conferência chamada de Conferência de Tbilisi, a mesma veio para definir o rumo da EA, e em 31 de agosto de 1981 é sancionada a Lei $n^{\circ}$ 6.938, a mesma dispõe seus fins e mecanismos de formulação e aplicação, sobre a Política Nacional do Meio Ambiente. A partir da confecção de leis, conferências, dentre outros documentos relacionados à $E A$, inicia - se uma preocupação atinente com os aspectos ambientes, e vale salientar que dois graves acidentes, coloca em destaque o assunto abordado, como o da fábrica da Union Carbide, em Bhopal, Índia e na usina de Chernobyl, na capital da República da Ucrânia na União Soviética (DIAS, 2013).

O Plenário do Conselho Federal de Educação (MEC) aprova o Parecer 226/87, que inclui a EA nas propostas curriculares das escolas de $1^{\circ}$ e $2^{\circ}$ graus, neste mesmo ano é assinado o Protocolo de Montreal, que possui a finalidade de evitar a destruição da camada de ozônio. Em cinco de outubro de 1988 é promulgada a Constituição Federal, contendo um capítulo abordando sobre o meio ambiente, pois considera se assuntos associados ao meio ambiente essenciais para a qualidade de vida, em seguida a Lei 7.335, de 22 de fevereiro de 1989 cria o lbama.

Em 1991, a Portaria 678 do MEC (14/05/91) resolve que a EA seja em todas as instâncias, níveis e modalidades de ensino e a Portaria 2421 do MEC, cria um grupo permanente para implementar metas e estratégias de EA no Brasil.

$\mathrm{Na}$ Conferência Rio - 92 percebeu se que o documento vigente precisava ser reformulado para a sustentabilidade e adaptado à realidade brasileira, e foi criado o Plano de Ação, a Agenda 21 (DIAS, 2013).

No dia 10 de maio de 1993 é instituída outra Portaria do MEC, para concretizar ás recomendações ocorridas na Conferência Rio-92. Um avanço para a composição curricular foi no ano de 1993 que foi elaborado novos 
Parâmetros Curriculares do MEC que inclui o tema meio ambiente como tema transversal do currículo.

Devido ao consumo desenfreado e a importância de se trabalhar EA na formação do cidadão, em 1999 é promulgada a Lei 9.795 de 27.04.1999, Política Nacional de Educação Ambiental, ao qual oficializa e reconhece a EA como um processo essencial na educação e por fim no ano de 2000 acontece o Conselho de Berlim, que reúne os países da G-8 para encontrar formas mais modernas para a redução do impacto no meio ambiente, portanto atualmente a EA se tornou uma ferramenta indispensável para a evolução do ser humano (DIAS, 2013).

\section{Operacionalização no ensino da Educação Ambiental}

Conforme 0 artigo $1^{\circ}$ da Lei $n^{\circ} 9.795 / 99$, percebe-se que se extrai deste artigo os princípios, objetivos, âmbitos envolvidos, os atores responsáveis pela implementação e principais linhas de ação para efetivar o processo de conscientização ambiental.

Primeiramente, para trabalhar-se a EA deve-se relacionar com o "porquê". Neste momento requer que as reflexões ambientais estejam vinculadas com o processo de formação social e a relação ambiente sociedade na comunidade escolar, sendo necessário contextualizar, valorizar, averiguar as bases de conhecimentos do discente. Como refere se Calvacante (2005) "a Educação Ambiental é território de todos e deve ser trabalhada com responsabilidade a partir de uma visão de mundo e sociedade que está inserida no projeto político pedagógico do espaço no qual atuamos".

A despeito dos âmbitos envolvidos nesse processo de sistematização da EA entende-se a importância da inter-relação de cada indivíduo com os aspectos sociais, culturais, políticos e econômicos de cada local, portanto a materialização dessa visão é a reciprocidade entre si e a natureza envolvendo a coletividade como um todo. Contudo, devido a esta imensa relevância com o meio ambiente existiu a preocupação em promover o conhecimento em EA, este reconhecimento se constitui por Lei conforme dispõe as Diretrizes Curriculares Nacionais para a Educação Básica que em todas as suas etapas e modalidades, ministrada em todos os níveis de ensino fundamental, médio e superior reconhecem a obrigatoriedade da EA, inserindo em seu currículo a orientação aos processos de aprendizagem. Ao se tratar do espaço escolar que compreende a equipe pedagógica, professores, alunos, pais, familiares, comunidade e poder público que trabalhando em prol do bem comum podem atender os anseios de um exercício a cidadania.

$O$ processo de expansão da EA tem sido fundamental diante do contexto atual, portanto os atores responsáveis para essa disseminação encontram-se na escola, visto que é a base para a formação social, no qual possui a missão de promover á ética e a cidadania ambiental, adotando uma abordagem com a interface globalizada. 
A medida que a escola, a comunidade e o poder púbico compreendem com a função essencial para efetivar a aprendizagem significativa da EA, como segue descrito na Resolução Conama $n^{\circ} 422$, de 23 de março de 2010, em seu Art. $1^{\circ}$, que visa estabelecer diretrizes para conteúdos e procedimentos em ações, projetos, campanhas e programas de informação, comunicação e Educação Ambiental no âmbito da educação formal e não formal, realizadas por instituições públicas, privadas e da sociedade civil, sendo assim claro a ação conjunta das linhas de ação referentes à EA.

Não obstante, as práticas pedagógicas devem considerar as propostas curriculares como o Projeto Político Pedagógico (PPP), que oferece o suporte basilar para a elaboração de ações pedagógicas, bem como projetos educativos para a aprendizagem, além de ser confeccionado na coletividade, observando a realidade de cada escola e dos Projetos e Planos de Cursos (PC) das instituições de Educação Básica.

Para que se atinja e torna-se efetiva a EA os órgãos normativos e executivos do sistema se articulem para a formação e capacitação dos profissionais da educação munindo de saberes didáticos-pedagógicos da dimensão acadêmica e escolar, garantindo um ensino de qualidade e atualizado, desde que aliado ao previsto na Resolução do CNE $N^{\circ} 02$, de 15 de Junho de 2012, que estabelece as Diretrizes Curriculares Nacionais para a Educação Ambiental, no Art. 14, inciso II, contempla com uma abordagem curricular integrada e transversal, contínua e permanente em todas as áreas de conhecimento, componentes curriculares e atividades escolares e acadêmicas, portanto deixando explicito o papel indispensável da equipe pedagógica e comunidade.

Por fim, a conscientização da sociedade sobre o tema Meio-Ambiente é concreta quando as metodologias de EA são trabalhadas, contextualizadas e abordadas no processo educacional que se inicia na escola por meio de enfoques interdisciplinares, em que 0 fortalecimento da ação conjunta representa a participação ativa de cada indivíduo e da coletividade para a transformação social.

\section{Resultados}

\section{Ações desenvolvidas}

Os sujeitos deste artigo são as equipes pedagógicas das EF do município de Montanha, ou seja, os resultados e suas respectivas abordagens são indicativos de como trabalham a questão da EA com os discentes, como relacionam este tema com a comunidade e se existe atendimento aos parâmetros legais pertinentes à EA.

Para verificar essas abordagens as escolas de EF do município de Montanha mencionadas neste trabalho, responderam ao questionário em anexo (Apêndice A), pelo qual foi possível constatar, de forma unânime, que todas as escolas realizam ações semelhantes devido possuírem como referência a Comissão de Meio Ambiente e Qualidade de Vida na Escola

revista brasileira educação ambiental 
(COM-VIDA) uma proposta do Ministério do Meio Ambiente em parceria com o Ministério da Educação, que utiliza como fio condutor a questão socioambiental para a (re)aproximação escola-comunidade.

Neste sentido, ao questionar as escolas sobre as ações desenvolvidas para trabalhar a EA no ambiente escolar, obteve-se os seguintes resultados conforme demonstrado na Figura 1.

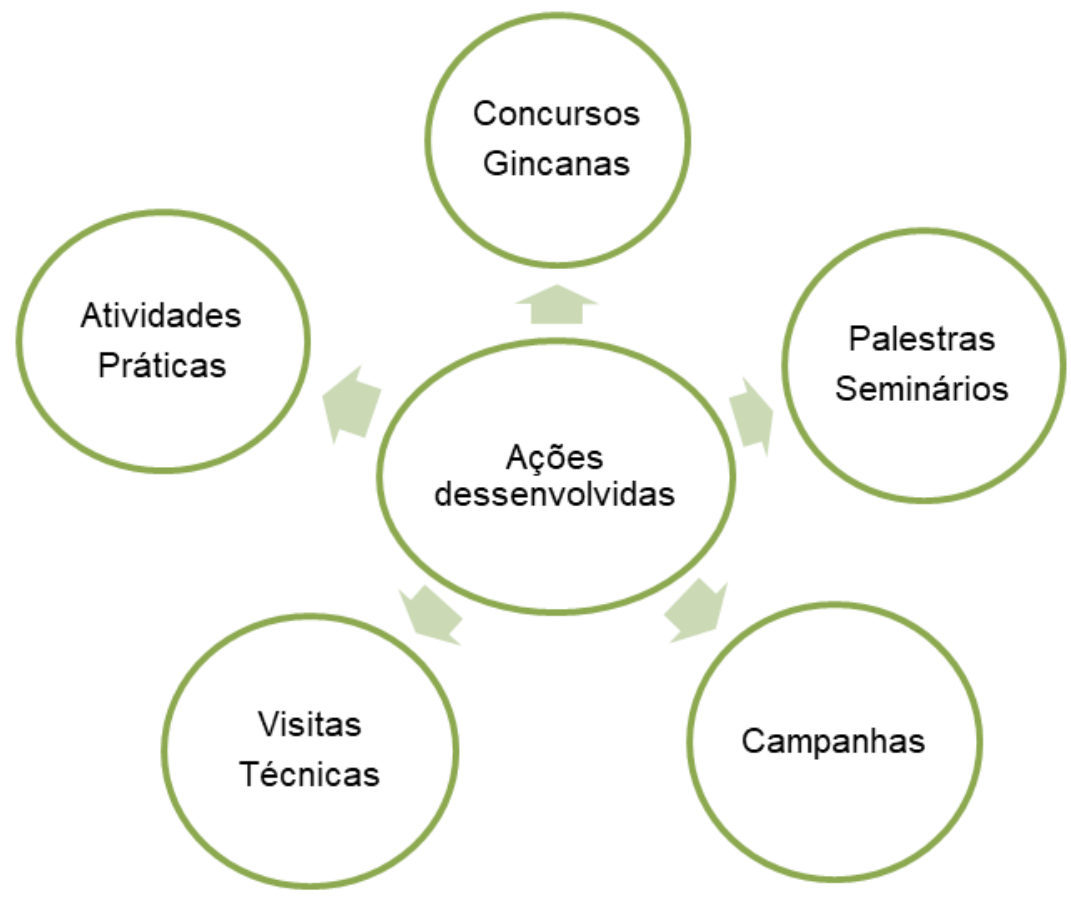

Figura 1: Ações desenvolvidas nas escolas de Montanha/ES.

Fonte: Autores.

As ações desenvolvidas foram atividades práticas, visitas técnicas, campanhas, palestras/seminários e concursos/gincanas, afirmando o ponto em que estas ações devem se relacionar com a sociedade as escolas coletam materiais recicláveis e realiza a feira de troca e revenda de resíduos por outros produtos, bem como vale ressaltar que estas ações ocorrem com uma frequência trimestral no município.

\section{Formação complementar para os docentes}

A atualização e aquisição de conhecimentos para serem trabalhados em sala de aula, são adquiridos através da formação inicial, continuada e complementar, no qual faz parte do percurso da vida profissional dos docentes, sendo de suma importância a complementação e continuação no processo de conhecimento.

A formação complementar é resguardada por leis, e sob a disposição 
Parágrafo único. Os professores em atividade devem receber formação complementar em suas áreas de atuação, com o propósito de atender adequadamente ao cumprimento dos princípios e objetivos da Política Nacional de Educação Ambiental.

Sobre as ações, a equipe pedagógica afirmou que o planejamento dos conteúdos da EA é trabalhado de maneira integrada com todas as disciplinas, compatível com o Art. 5 da PNEA em que em seu Inciso I fomenta a integração da EA às disciplinas de modo transversal, contínuo e permanente, bem como, estas atividades são discutidas no planejamento semanal, resultando em projetos e ações com a comunidade.

Quanto à oferta de formação complementar para os docentes, destacase a COM-VIDA, que é uma das ações estruturantes do Programa Vamos Cuidar do Brasil com as Escolas, sendo que esta consolidação tem como foco participativo, democrático, animado e saudável.

Diante disso, os investimentos em formação complementar que consta no currículo de formação dos docentes das escolas do município de Montanha são em cursos com temas que abordam a questão da $E A$, porém não existe, ainda, uma retribuição salarial para os participantes da capacitação.

\section{COM-VIDA}

A COM-VIDA possui um importante papel no que tange em promover relações entre a escola e a comunidade, envolvendo a comunidade escolar na solução de problemas atuais, tendo a iniciativa em reunir diversas pessoas para atingir um mesmo propósito, de um mundo melhor.

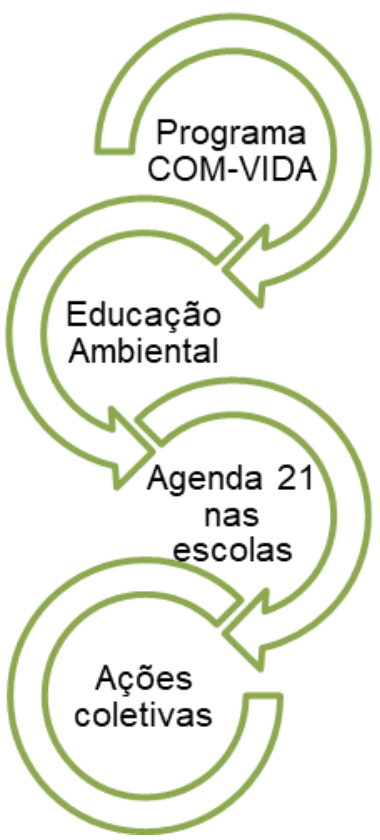

Figura 2: Organograma de procedimentos da EA pela COM-VIDA. Fonte: Autores.

Revbea, São Paulo, V.13, № 4: 66-78, 2018. 
A Figura 2, expressa o organograma em que consisti a COM-VIDA, sendo este diretamente relacionado com os princípios e objetivos da EA, bem como em construir a Agenda 21 nas escolas como um instrumento de auxilio as escolas, resultando em ações coletivas com a comunidade e aprofundando no compromisso com o meio ambiente.

As escolas propõem palestras com profissionais externos ao ambiente escolar e promovem visitas técnicas para colaborar e elevar a aprendizagem dos alunos com relação à questão ambiental, bem como existe um responsável pela COM-VIDA como o Coordenador do Meio Ambiente, para assim manter articulada, a ideia de Círculo de Aprendizagem e Cultura, proposto por Paulo Freire, do qual ele refere-se como um lugar onde todos têm a palavra, lêem e escrevem o mundo. Sendo um espaço de trabalho, pesquisa, exposição de práticas, dinâmicas, que possibilitam a construção coletiva do conhecimento, no qual pode ser associado com o está expresso no tópico Fundamentos Conceituais e Metodológicos da COM-VIDA.

\section{Resultados das ações de Educação Ambiental praticadas em Montanha-ES}

Para constar a eficácia e eficiência do assunto da EA a ser trabalhado no EF e quão visíveis e benéficos são os resultados atingidos ao longo deste processo, vale ressaltar o quanto o nome do município de Montanha foi elevado e reconhecido devido às ações pertinentes a prática da EA.

No estado do Espírito Santo, o município de Montanha é considerado como referência de "Cidade Limpa", bem como é uma das únicas cidades do estado que possui o sistema de coleta seletiva e unidade de triagem e compostagem em funcionamento, devido às estas ações foi publicado em capa de matérias de jornais nacionais, como o Globo News, sobre atuações na área de sustentabilidade.

O município de Montanha também investe em desenvolvimento de projetos, como por exemplo "Moeda de Troca", cuja a intenção é educar a população a colaborar com as normas da coleta seletiva do lixo domiciliar, separando-os corretamente, além ser efetivar uma parceria entre as escolas e alunos com o aplicativo "E-Sustentável" que possui o objetivo de auxiliar os municípios no descarte do lixo reciclável.

Portanto, devido a estas ações apresentadas comprova-se o quanto o ensino da EA realizado de forma eficaz no EF do município de Montanha desde o ano de 2009, produz resultados satisfatórios.

\section{Conclusões}

O desenvolvimento deste artigo propiciou uma análise das concepções sobre a EA nas escolas de EF do Município de Montanha, abordando as metodologias que as mesmas ofertam e praticam no ensino da EA, na busca da formação crítica e humana de discentes. Também, tornou-se fio condutor para a realização do mesmo, o fato de que o docente ainda encontra 
dificuldades para abordar a EA na sala de aula, sendo que à busca por novas metodologias são necessárias para potencializar o ensino da EA.

Ao analisar o questionário, percebeu-se que as equipes pedagógicas das escolas que oferecem o EF no município de Montanha, desenvolvem a coletividade, a transformação social, trabalham conteúdos referentes EA com interdisciplinaridade e a favor das diretrizes, ofertam especialização em prol da formação complementar dos docentes, além do que, desenvolvem atividades e projetos voltados para a EA.

A aplicação do questionário fechado mostrou também, que as equipes pedagógicas das escolas de EF do município de montanha, possuem conhecimento à cerca de que a EA precisa ser trabalhada dentro do contexto escolar, bem como na comunidade, propiciando ao discente uma consciência crítica na busca de sua transformação social.

A LDB em sua Lei ํo 9.394/96 e no 10.172 , reforça em relação à vinculação da escola com a comunidade e estabelece a criação de processos formativos, a fim de unir ambos os lados, a partir de comissões escolares ou órgãos equivalentes, onde devem ser apoiadas e incentivadas.

Contudo, evidencia-se que existe uma busca constante, por novas formas de abordar as questões ambientais por parte destas escolas. Toma-se como exemplo a COM-VIDA, que o município, vem tomando como referência e desenvolvendo em suas escolas de EF na aplicação da EA.

A COM-VIDA oportuniza jovens, professores (as), gestores (as) e comunidades, a opinar, reunir e debater sugestões de como cuidar do Brasil e dos problemas socioambientais, onde sua criação contribui para ajudar a por em prática várias propostas abordadas. Além de tudo, objetiva ainda transformar escolas em espaços de mobilização, locais para atuação e aprendizado referentes ao meio ambiente e em prol da melhoria da qualidade de vida. O mesmo tem dado conta de mobilizar e envolver escolas e comunidades, transpassando os muros das escolas, afim de, somar forças com outras organizações, com intuitos e propósitos bem viáveis.

Contudo, as metodologias aplicáveis adotadas pelas escolas de EF do município de Montanha-ES, referentes à EA, servem de modelo para outras escolas de outros municípios, embasarem como a EA deve ser implantada. Isto é, as escolas podem seguir um projeto padrão para as mesmas, tendo como base de sustentação a COM-VIDA, utilizada pelo município de Montanha-ES.

\section{Referências}

BRASIL. Constituição Federal, 1988. Disponível em <www.planalto.gov.br/ ccivil 03/constituicao/constituicaocompilado.htm>. Acesso em: 23/04/17.

BRASIL. Lei 9795, de 27 de abril de 1999. Dispõe sobre a Educação Ambiental, institui a Política Nacional de Educação Ambiental e dá outras providências. Disponível em: <http://www.planalto.gov.br/ccivil 03/leis/L9795. $\underline{\mathrm{htm}}>$. Acesso em: 19/04/17.

revista brasileira educação ambiental 
BRASIL. Lei 9795, de 27 de abril de 1999. Dispões sobre a Educação Ambiental, institui a Política Nacional de Educação Ambiental e dá outras providências. Disponível em: <http://www.planalto.gov.br/ccivil 03/leis/L9795.htm>. Acesso em: 23/04/17.

BRASIL. Ministério Da Educação, Coordenação Geral De Educação Ambiental: Ministério Do Meio Ambiente, Departamento De Educação Ambiental. Vamos Cuidar do Brasil : conceitos e práticas em Educação Ambiental na escola. [s.e], Brasília, DF, 2007. Disponível em: <http://www.ebah.com.br/content/ ABAAAAO60AJ/educacao-ambiental-na-escola?part=2> .Acesso em: 23/04/17.

BRASIL. Ministério da Educação. Secretaria de Educação Continuada, Alfabetização e Diversidade. Formando Com-Vida Comissão do Meio Ambiente e Qualidade de Vida na Escola: construindo Agenda 21 na Escola. [s.e], Brasília-DF, 2004. Disponível em: <http://www.mma.gov.br/ estruturas/educamb/ arquivos/com-vida.pdf>. Acesso em: 23/04/17.

BRASIL. Parâmetros Curriculares Nacionais (PCNs). Meio Ambiente e Saúde. Brasília: MEC/SEF, 2001. v9. p.24-29.

DIAS, G.F. Educação Ambiental: princípios e práticas. 9. ed. São Paulo: Gaia, 2013. p. $83-124$.

DIAS, G.F. Educação Ambiental: princípios e práticas. 9. ed. São Paulo: Gaia, 2013. p. $24-73$.

GUIMARÃES, M. (Org) et al. Caminhos da Educação Ambiental: da forma à ação. 3. ed. Campinas, São Paulo: Papirus, 2008. Disponível em: $<$ https://books.google.com.br/books? id=Oc88qzmn5ewC\&printsec=frontcover\& dq=educa $\%$ C3\%A7\%C3\%A3o+ambiental\&hl=ptBR\&sa=X\&ved=0ahUKEwiBx9 ndj57UAhUElpAKHRFtBagQ6AEIOjAF\#v=onepage\&q=educa\%C3\%A7\%C3\%A 30\%20ambiental\&f=true $>$. Acesso em: 03/06/17.

HANSEN, K.S. Metodologias de ensino da Educação Ambiental no âmbito da Educação Infantil. Disponível em:<http://www.revistaea.org/artigo.php? idartigo $=1467>$. Acesso em: 03/04/17.

LOUREIRO. C.F. (Org.) et al. Sociedade e Meio Ambiente: a Educação Ambiental em debate. 7. ed. São Paulo,SP: Cortez.2012. p. 134 - 160.

OLIVEIRA, Ma.F. Metodologia científica: um manual para a realização de pesquisas em administração. Catalão, Góias, 2011. Disponível em: $<$ https://adm.catalao.ufg.br/up/567/o/Manual de metodologia cientifica -

Prof Maxwell.pdf >. Acesso em: 23/04/17. 